\title{
Кудрявцева К.Г. \\ Эден. «Где-то на белом свете» Мифологема сада в Библии
}

\author{
Институт Святого Фомьи \\ (Россия, Москва) \\ doi:10.18411/lj2016-4-11
}

Образ земного рая или города, или волшебного замка, расположенных на стыке миров, находящихся «в одно и то же время близко и очень далеко от нас» получает особое развитие в культуре. Туда можно стремиться, но практически невозможно попасть. Место это всегда укреплено и охраняемо. Часто - невидимо. Там своё измерение реальности, неподвластное обычному ходу времени. Этот образ является и символом плодородия и местом смерти. Образ сопровождается рядом мифологем - вода (символ плодородия, в ряде случаев - ограды), гора (как символ соединения двух миров).

Приведём несколько примеров из различных традиций. В иранских текстах местом, эквивалентным мифическому саду, становится замок Кангдиз, построенный Каем Хосрау. Замок укреплён, труднодоступен и невидим. Его обитатели не знают старости и смерти. Прежде чем попасть в Кангдиз, Кай Хосрау сам купается в источнике и становится невидимым. Кай Хосрау строит храм, посвящённый царскому Огню, и делает его невидимым до дня Воскресения. Тот, кто попадает в Саррас, становится невидимым для других. Невидимость тут является аналогом смерти, или, говоря на языке мифологии, - вечной жизни.

В христианском тексте «Хождении Агапия в рай» Агапий, переправившись по морю, приходит к «стенам, которые стоят от земли до неба», к месту, к которому «никто не приходил в [человеческом] облике». Старец Илия, который проводит Агапия внутрь, говорит: «Эти же все, которых ты видишь - души человеческие. Этот источник, который видишь, - называется рай, и течёт под деревья райские. Этот свет ангельский и праведных душ

В традиции иудаизма таким раем-садом становится сад Эден».

Согласно Быт., «... произрастил Господь Бог из земли всякое дерево, приятное на вид и хорошее для пищи, и дерево жизни посреди рая, и дерево познания добра и зла.10 Из Едема выходила река для орошения рая; и потом разделялась на четыре реки.11 Имя одной Фисон: она обтекает всю землю Хавила, ту, где золото;12 И золото той земли хорошее; там бдолах и камень оникс. 13 Имя второй реки Гихон: она обтекает всю землю Куш.14 Имя третьей реки Хиддекель: она протекает пред Ассириею. Четвертая река Евфрат» (Быт. 2:10-14).

Локализация Эдена достаточно проблематична. С одной стороны, две реки известны - Тигр и Евфрат. С другой стороны, реки Гихон и Пишон совершенно неизвестны. Идентификация этих рек различна. Гихон часто отождествлялся с Нилом, а Пишон с Гангом. Например, Иосиф Флавий в «Иудейских Древностях» говорит: «Этот сад был орошаем рекою, которая обтекает вокруг всей земли и распадается на четыре рукава: Фисон (имя это обозначает «множество») течет по направлению $\kappa$ Индии и впадает в море, называется греками Гангом; Евфрат и Тигр текут в Красное море» (Иуд. др. 1,1:3).

По мнению Дитриха, эти две реки относятся к рекам Улай (греч. Улайос, сейчас Керхе) и Укну (сейчас Карун). Археолог Юрис Заринс считает, что место, в котором располагался, согласно Быт., Эден, - это южный берег Персидского залива, Гихон - это современная иранская река Карун, а Пишон - высохшие сейчас реки Вади Батин и Вади Риниах. Исследователь Д.Дж. Хамблин считает, что Эден находился в том месте, где сливаются реки Тигр и Евфрат и переходят в реку Шатт-эль-Араб, впадающую в Аравийское море.

Тем не менее расположение сада Эден в Быт. остаётся неясным. Хотя, может быть, эта неясность предусмотрена автором текста. Тем самым, Эден предстаёт полуреальным местом.

Согласно комментарию Сончино, «После того, как Адам согрешил, насаженный Всевылним сад, представлявший собой идеальный мир, был скрыт от человека полностью и не может ассоциироваться ни с одним местом ни на земном 
шаре, ни во всем материальном мире. Сад Эден остался в области идеальных духовных миров и служит местом пребывания душ праведников до исправления всего Творения, в том числе и мира грубой материи».

Как отмечает Стордален, сад Эден - некое место, находящееся за пределами обычного мира, «возможно, на дальнем берегу космического океана», место на стыке миров.

«И насадил Господь Бог рай в Едеме на востоке» (Быт. 2:8). Перевод слова $\sim \mathrm{d}<\mathrm{Q}<+\mathrm{mi}$ «на востоке» не является единственным. Ещё одно значение слова - «оттуда, где раньше». Так в Библии обозначаются первые пространственно-временные характеристики, хотя и достаточно условные. А введение географических деталей, по мнению М. Каспиной, было призвано «помочь читателю соотнести знакомые ему элементы ландшафта с пра-пространством и пра-временем».

На временное понимание локализации Эдена указывает и комментарий Сончино, где «восток» рассматривается как «та сторона света, где раньше появляется солнце». Комментарий ссылается также на Онкелоса, который «переводит "до начала времен", указывая тем самым на то, что история человечества как таковая начинается в более поздний момент».

Стордален отмечает сходство сада Эден с такими мифическими садами, как кедровый лес и сад драгоценных камней из «Эпоса о Гильгамеше». Ван дер Койдж прибавляет к этому трактовку сада Эден как царского парка и шумерскую историю о потопе, в которой Зуисудра становится бессмертным, и боги поселяют его на востоке, на острове Дильмун.

Оба места находятся где-то «на востоке», что очень напоминает мифический город, страну на востоке, находящуюся на стыке миров. Оба места связаны с водой. На Дильмуне много сладкой воды. Сад Эден омывается четырьмя реками. Оба места напоминают «незапущенную» картинку. И там, и там как бы нет движения, они вне времени или перед временем. В шумерском мифе история начинается тогда, когда Дильмун наполняется пресной водой, Нинхураг начинает выращивать растения и предрекает смерть Энки, съевшего эти растения. В библейском пассаже жизнь и смерть появляются вместе с поеданием Евой и Адамом плода с древа познания добра и зла и последующим проклятием Бога, предрекающим им смерть.

Создание человека в библейском повествовании происходило за пределами Эдена: «И насадил Господь Бог рай в Едеме на востоке, и поместил там человека, которого создал» (Быт. 2:8).

Сад не является местом рождения человека (мужчины). Но остаётся по отношению к нему тем местом, которое можно достичь или потерять. Создание Евы, наоборот, происходит уже в Эдене. Быть может, здесь видны отголоски представлений о женщине-саде.

Райские места ТаНаХа

Описания сада Эден, кроме Быт., встречается у пророков - Ис. и Иез.

В Ис., в 51-й главе гора Сион становится садом Эден: «Господь утешит Сион, утешит все развалины его и сделает пустыни его, как рай, и степь его, как сад Господа» (Ис. 51:3).

Упоминание о саде, как о месте, находящемся на горе, есть в 28-й главе Иез.: «Tbl находился в Едеме, в саду Божием... 14 Tы был помазанным херувимом, чтобы осенять ... ты был на святой горе Божией, ходил среди огнистых камней (Иез. 28:1314).

В Иез. вся земля уподобляется Эдену: «Так говорит Господь Бог: в тот день, когда очищу вас от всех беззаконий ваших и населю города, и обстроень будут развалины, 34 И опустошенная земля будет воздельвваема, быв пустынею в глазах всякого мимоходящего, 35 Тогда скажут: «эта опустелая земля сделалась как сад Едемский...»» (Иез.36:33-35).

Здесь нет упоминания о Сионе, но, как отмечает Ван Руитен, «вся земля» включает в себя Сион.

В Иез. 28 Эден назван «садом Божием» (Иез. 28:13) и «святой горой Божие» (Иез. 28:14). В стихе 18-м Бог говорит Сатану: «18 ...mbl осквернил святилища твои» (Иез. 28:18). 
Слова «святилища твои» (mikdasheiha)i, по всей видимости, относятся здесь именно к Эдену. Примечательно, что слово vD'q.mi в ТаНаXе применяется и в отношении Скинии (Исх. 25:8), и Храма в Иерусалиме (Иез. 45:3), и всей земли (Исх. $15: 17)$.

Помимо этих фрагментов, где явно упомянуто название «Эден», отметим и другие родственные фрагменты.

В Иез. (главы 40-47) дано описание будущего Храма. Пророк поставлен «на весьма высокой горе, и на ней, с южной стороны, были как бы городские здания» (Иез. 40:2). В 47-й главе воды реки выходят из святилища. По берегам этой реки «много было дерев» (Иез. 47:7), и на берегах «будут расти всякие дерева, доставляющие пищу: листья их не будут увядать, и плоды на них не будут истощаться; каждый месяи будут созревать новые, потому что вода для них течет из святилища...» (Иез. 47:12). Упоминание реки и изобилия деревьев напоминает райский сад Эден.

Ещё один интересный отрывок - Ис. 65:17-25, где даётся описание новых небес и земли. В описании «новой земли» явно используются элементы сада: «21 ...И насаждать виноградники и есть плоды их...25 Волк и ягнёнок будут пастись вместе, $и$ лев, как вол, будет есть солому, а для змея прах будет пищею...» (Ис. 65:21, 25).

Итак, сад Эден в ТаНаХе наполнен водой, противопоставляется пустыне и связывается с некоторой возвышенностью, горой. Наряду с описаниями «предвременного» Эдена происходит также перенос сада в будущее, в конец времён. И здесь сад связывается или с горой Сион, или вся земля Израиля становится садом. Также присутствует некоторая связь Эдена с Храмом. Хотя прямого отождествления нет.

«Распрекрасная та благодать». Эден в апокрифах и псевдоэпиграфах

В ТаНаХе, кроме некоторых деталей описания будущего Храма в Иез. , нет прямого отождествления сада Эден с Храмом. В Быт. Эден предстаёт как место пребывания человека, некое идеальное место, но не как святыня. Нигде в ТаНаХе Эден не употребляется в контексте со Святая Святых или с «местом, пребывания Бога».

Первым текстом, в котором сад Эден явно приравнивается к Храму и наделяется его чертами, становится ветхозаветный апокриф - Книга Юбилеев.

Эден в Юб., по всей видимости, располагается на горе. Наряду с горой Востока (идентификация этой горы представляет определённую проблему), Синаем и Сионом, Эден назван одним из мест, которые принадлежат Богу (гл. 4). В 8-й главе говорится только о трёх святых местах:

«... Сад Эден - Святая Святых и место пребывания Бога. Гора Синай - в середине пустыни, и гора Сион - в иентре пупа земли. Эти три были созданы как святые места - одна напротив другой» (Юб. 8:19). Можно предположить, что и сад Эден располагается на горе. Тем более это вполне логично вписывается в описание «Эти три... - одна напротив другой» (Юб.8:19).

Благодаря сравнению с наиболее святой частью Храма, Святая Святых, и перечислению наряду с горой Сион Эден напрямую приравнивается к Храму.

В Юб. можно отметить особый акцент на воздвижении будущего эсхатологического Храма: «... от первого творения до того времени, когда мой Храм будет построен среди них навечно...» (Юб.1:27).

При этом текст явно отрицательно относится к Первому и Второму Храму. Положительно Юб. говорят только о святынях либо до строительства Храма, либо о будущем Храме.

Юб. не только уподобляют Эден Храму и ставят акцент на роли эсхатологического Храма, но и выделяют Эден среди остальных святынь. Так, Эден, как уже было сказано, приравнивается к самому святому месту - Святая Святых (Юб. 8:19). Эден и Храм - это места пребывания Бога. «Я построю Своё святилище среди них и буду пребывать с ними» (Юб. 1:17)

Понимание Эдена как Храма вполне соответствует тому, что Адам приносит жертву после своего изгнания из Эдена, выступая как первый священник: «B тот день, когда Адам вышел из сада Эден, он принёс жертву благовонную: ладан, гальбан, стакти и сенегал - утром с восходом солнца, в день, когда он покрыл свою срамоту» (Юб. 3:27). 
Такое жертвоприношение (только не утром, а вечером) приносит и Енох, который, согласно Юб., предстаёт некой «моделью для последующего священства».

Подтверждением отождествления Юб. Эдена со Святая Святых может быть теория М. Харана о двух типах жертвоприношений. По мнению учёного, текст Исх., дающий два описания жертвенника, подразумевает наличие двух типов воскурений. Одно совершалось на жертвеннике внутри скинии, другое - во дворе перед скинией. Воскурения во дворе никогда не сопровождались в описаниях эпитетами, тогда как воскурения во внутреннем дворе, Святая Святых, обозначались как «воскурение саммим», где «саммим»- специи, добавляемые к елею и не используемые в обычных воскурениях. Так и в случае жертвоприношения Адама - в Юб. мы можем наблюдать конкретизацию компонентов жертвы.

Конкретизация благовоний появляется и в упоминание жертвы Авраама. Но это не является показателем того, что Авраам находится в Эдене. Если в случае с Адамом приводятся те же четыре компонента, как в Исх. 30:34, то Авраам смешивает гораздо больше - семь. А это уже не совсем та жертва, которая приносилась перед Святая Святых. Также, помимо воскурения благовоний, Авраам приносит жертву всесожжения, которая, как известно из Исх. (Исх.30:9), совершалась за пределами скинии: «Это - всесожжение постоянное в роды ваши пред дверями скинии... » (Исх. 29:42). Именно эта деталь - принесение жертвы всесожжения - и является основным показателем, что действие Авраама не приравнено к тому, что происходит перед Святая Святых.

Ной тоже приносит жертву на горе. Но это жертва - опять-таки жертва всесожжения. Ной приносит в жертву благовоние, и никакой конкретизации компонентов здесь нет: «... и вознёс приятное благоухание, которое было приятно Господу» (Юб. 6:3). Кроме этого, Ной «положил на алтарь мясо и «возлил вино...» (Юб. 6:3), что напоминает описание ежедневной жертвы, которая так же, как и жертва всесожжения проводилась не в самой скинии, а на жертвеннике, стоящем «пред дверями скинии» (Исх. 29:42). Хотя в описании ежедневной жертвы отсутствует упоминание о плодах (см. Исх.29:38-42). Юб. Говорят о плодах позже - в 7-й главе, когда Ной производит приношение, посадив виноградник и собрав первые плоды. Здесь эта жертва, по-видимому, связана с праздником первых плодов. В обоих случаях Ной никак не связан с Эденом, а находится на горе Любар, где остановился ковчег.

В Юб. разница в месте совершения жертвы как раз и показана через разный тип жертв, одна из которых совершается перед Святая Святых, а другая - во внешнем дворе.

Кроме того, автор Юб. переносит мотив создания и «познания» Адамом Евы за пределы сада, до их входа в Эден. И на Эден переносятся законы, касающиеся Храма (или законы Храма объясняются через Эден). Так, женщина не может входить в святилище, в Храм после рождения сына - 33 дня, дочери - 80 дней, потому что Ева вошла в Эден через 80 дней после своего творения: «После того, как она завериила те 80 дней, мы взяли её в сад Эден, потому что это место святее любого другого на земле, И каждое дерево, которое посажено в нём, - свято. 13 Поэтому закон этих дней установлен для любой, которая рождает мальчика или девочку. Женщина не может прикасаться ни к какой святой вещи и не может входить в святилище) до тех пор, пока не закончатся те дни...» (Юб. 3:12-13).

В этом отрывке Эден назван самым святым местом не земле, что можно сравнить с главой 8 , где об Эдене говорится как о Святая Святых - самой святой части Храма.

Апокрифы и псевдоэпиграфы следуют за библейским повествованием, описывая Эден как сад со множеством деревьев. В нём есть источник (один или несколько). Добавляется ещё несколько деталей. Во-первых, это расположение сада на горе. Во-вторых, появление драгоценных камней и металлов, которыми полон сад или райская гора. Часто вместе с раем даются описания ада, составляя своего рода вторую половину раю. При этом их описания в некоторых текстах практически параллельны.

В 1Ен. во время своего небесного путешествия Енох видит небеса. Не раз повторяется описание гор. Так, в 18-й главе «в месте, которое горит день и ночь» (1Ен.18:6), ему открываются семь гор из драгоценный камней. Средняя из них, «достигшая неба, как престол Божий, была из алебастра, и вершина престола из 
canфuра (1Ен.18:8). В 24-й главе Енох восходит на горящий горный хребет, откуда видит семь гор, вершина одной из них подобна «тронному седалищу, которое окружено было благовоннылми деревьями» (1Ен. 24:3). В 32-й главе Енох, проходя через очередные семь гор, «изобиловавщие драгоиенными нардами, и благовонными деревьями, и корицей, и перцем» (1Ен. 32:1), идёт на вершину этих гор, на Восток, и приходит в «cad правдbl», в котором растёт множество деревьев и дерево мудрости. О «саде жизни», в котором живут избранные, есть упоминание в 61-й главе (1 Ен. 61:12). О «саде», в котором живут избранные и праведные, говорится также в 60-й главе (1 Ен. 60:8). Параллельно местам, отведённым праведникам, присутствуют и места для грешников. В основном это долины, либо ущелья. Например, в главах 26-27, после описания гор с престолом Бога и деревьями даётся изображение узкой долины, располагающейся между гор. "Та проклятая долина для тех, которые прокляты на века; здесь должны собираться те, которые говорят своими устами непристойные речи против Бога и дерзско говорят о его Славе...» (1 Ен. 27:2).

Более развёрнутое описание рая-сада присутствует во 2Ен., когда Енох достигает третьего неба: «Вид же места того красоты незнаемой есть: всякое древо иветами украшено, всякий плод наливается, всякое брашно кипит изобилием на всякое время, всякое веяние благовонно, и четыре реки мимотекущие, тихо шествующие, всяк злак добр на пищу порождающие. И Древо жизни на месте том, где почиёт Господь, когда входит Господь в Рай, и древо то отменно благовонием своим несказуемым. И другое древо подле, масличное, точащее елей непрестанно. И всякое древо благоплодно, и нет там древа бесплодного, и на всём месте там благословение. Ангель же, хранящие Рай, светлые весьма, немолчными гласами сладкопения своего служат Бог на всякое время». Это благодатное место приготовлено для праведников «в наследие вечное» (2Ен, гл. 5).

Сразу за описанием рая следует описание другого места: «... и вознесли меня на север неба, и показали мне там место, страшное весьма. Всякое мучение и терзание на месте том, и нет там света, но огонь мрачный... и река огненная, заливаюшая все места те, студёный лёд, и узилиша, и ангелы лютые и немилосердные, носящие оружие и мучаюшие без милости». Место это приготовлено для грешников «в удел вечный» (2 Ен., гл.5). И в 1Ен., и во 2Ен. в описании сада большое внимание уделяется деревьям, среди которых растёт древо жизни. Место это предназначено для праведников и находится за пределами (или на стыке) нашего мира. Никакого совмещения с землёй Израиля или же Храмом здесь нет.

В Откровении Моисея, тексте, который, вероятно, восходит к дохристианскому времени, и в основе которого лежат видения из иудейской традиции, Бог говорит Моисею, что создал два парка - рай и ад (гл. 30). Эти два места становятся как бы абсолютно параллельными друг другу, двумя полюсами в одном. В описании рая, как и в предыдущих текстах, появляются драгоценные камни и металлы. Здесь из них сделаны семьдесят тронов, предназначенные для праведников. В раю растёт древо жизни, из корней которого вытекает живая вода, разделяется на четыре потока и через трон славы окружает весь рай. По каждым троном течёт четыре реки - из мёда, молока, вина и бальзама, протекая под ногами праведников, восседающих на тронах. Согласно тексту, рай не может быть измерен, он не имеет границ.

В тексте Откровения Иешуа бен Леви (вариант В) через рай протекают опять же четыре реки - из масла, из бальзама, из вина и из мёда, там растут розы и мирт, через которые натянуты пологи с висящими на них жемчужинами, «каждая из которой сверкает как утренняя звезда» (Откровение Иисуса, сына Леви (Б) 2). Там нет ночи. Рай, как и Откровении Моисея, разделён на семь частей. На семь частей разделён и параллельный раю ад.

Итак, мы рассмотрели ряд сюжетов из Танаха и апокрифической литературы, в которых рассматривается образ сада Эден. Мы видим параллели с сюжетами других традиций и появление черт, характерных для описаний некоего места, находящегося на стыке времён, труднодоступного рая (сада, города). Образ этот находит отражение в иудейской традиции и становится одним из основополагающих. Эсхатологические сюжеты используют темы Творения. Образ сада переходит на описания Храма и всей земли Израиля. Используя древние образы, ветхозаветная традиция создаёт новый образ, наделённый богословским содержанием. 


\title{
Список используемых источников информации
}

1. Вторая книга Еноха // От берегов Босфора до берегов Евфрата / пер., предисл. и коммент. С.С. Аверинцева. - М.: Наука, 1987. - С. 108-117.

2. Иосиф Флавий. Иудейские древности. В 2 тт. / пер. с греч. Г.Г. Генкеля. М.: Ладомир, 1994.

3. Каспина М.М Сюжеты об Адаме и Еве в еврейской и славянской традиции в свете исторической поэтики (На материале древней и средневековой книжности) / Дисс. к. филол. н. - М., 2001. - 251 л. - На правах рукописи.

4. Корбен А. Свет славы и святой Грааль / пер. с француз., англ. и фарси. - М.: Волшебная гора, 2006. $-224 \mathrm{c}$.

5. Пятикнижие и Гафтарот. Ивритский текст с русским переводом и классическим комментарием «Сончино» / комментарий составил д-р Й.Герц.- М: Мосты культуры; Иерусалим: Гешарим. 2001/5761.- $1456 \mathrm{c.}$

6. Харан М. Комплекс ритуалов, совершавшихся в храме / пер.Е.С.Сафронова // Библейские исследования: Сборник статей/ сост. проф. Барух Шварц. - вып.1.- Москва, 1997.

7. Хождение Агапия в рай // Апокрифы Древней Руси: тексты и исследования. - М.: Наука, 1997. (Общественная мысль: исследования и публикации) - С. 125-132.

8. Bible Works - ver. 7.0.012g

9. Dietrich M. Das biblische Paradies und der babylonische Tempelgarten. Überlegungen zur Lage des Gartens Eden / Das biblische Weltbild und seine altorientalische Kontexte / eds. B. Janowski und B. Ego. Tübingen: J.C.B.Mohr, 2001. (Forschungen zum Alten Testament 32). P. 281-323.

10. Grant R. J. Unveiling Mysteries of the Bible. Lausanne: Frontier Research Publications, 2013. P. 230 p.

11. Hamblin D. J. Has the Garden of Eden been located at last? // Smithsonian Magazine, 1987. Vol. 18. №2

12. Jubilees // The Old Testament Pseudepigrapha / ed. by J.C.Charlesworth. London: Darton, longman \& Todd, 1983. Vol. II. P. 52-142.

13. Gaster M. Hebrew Visions of Hell and Paradise //Journal of The Royal Asiatic Society. - London: The Royal Asiatic Society, 1893 (Scan. and ed. by C. M. Christopher, 2002). - P.571-611

14. Scott James M. On Earth as in Heaven: the Restoration of Sacred Time and Sacred Space in the Book of Jubilees//Supplements to the Journal for the Study of Judaism/ed. J.J.Collins, F.Garcia Martinez .- Leiden, Boston: Brill, 2005. - 292 p.

15. Stordalen T. Echoes of Eden: Genesis 2-3 and Symbolism of the Eden Garden in Biblical Hebrew Literature. - Leuven: Peeters, 2000. - 582 p. - (Contributions to Biblical Exegesis \& Theology, 25).

16. Ruiten J.A.T.G.M. van. Eden and the Temple: The Rewriting of Genesis 2:4-3:24 in the Book of Jubilees// Paradise Interpreted: Representation of Biblical Paradise in Judaism and Christianity/ ed. Luttikhuizen G.P.- Leiden: Brill, 1999. - P.215-227.

17. The Book of Enoch or 1 Enoch: a new English edition with commentary and textual notes// trans. M.Black in consultation with J.C.Vanderkam. - Leiden: Brill, 1985. - 467 pp. - (Studia in Veteris Testamenti Pseudepigrapha, vol. VII) - $467 \mathrm{p}$.

18. The Book of Jubilees: a critical text / ed. by J.C.VanderKam // Scriptores Aethiopici, tomus 87.- Lovanii, 1989. $-301 \mathrm{p}$.

\section{Ланге В.В., Романов В.В. \\ Оптимизация затрат на обслуживание трансформаторных подстанций}

\author{
ОГУ \\ (Россия, Оренбург) \\ doi:10.18411/1j2016-4-12
}

В работе рассмотрены вопросы оптимизации затрат на обслуживание ТП 6$10 / 0,4$ кВ, при сохранении уровня работоспособности оборудования ТП на высоком уровне. Произведена оценка затрат на их эксплуатацию с момента строительства, до момента демонтажа и обобщены факторы, определяющие величину затрат на обслуживание. Изложены основные технические характеристики и экономические показатели применения программно-аппаратного комплекса средств управления в трансформаторных подстанциях распределительных сетей.

\section{Основные вопросы проблемы снижения затрат на ремонт и обслуживание}

Не смотря на унификацию многих требований к управлению ремонтами, наличию надзорных органов, управление ремонтами и техническими службами можно организовать по разному, с разной эффективностью. 